\title{
Design and Technological Solutions for the Plasma Facing Components of WENDELSTEIN 7-X
}

\author{
J. Boscary ${ }^{\mathrm{a}}$, R. Stadler ${ }^{\mathrm{a}}$, A. Peacock ${ }^{\mathrm{c}}$, F. Hurd ${ }^{\mathrm{c}}$, A. Vorköper ${ }^{\mathrm{b}}$, B. Mendelevitch ${ }^{\mathrm{a}}$,

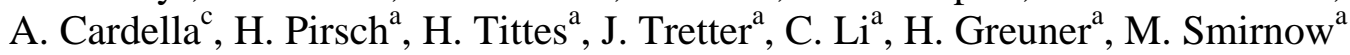 \\ ${ }^{a}$ Max-Planck-Institut für Plasmaphysik, EURATOM Association, 85748 Garching, Germany \\ ${ }^{b}$ Max-Planck-Institut für Plasmaphysik, EURATOM Association, 17491 Greifswald, Germany \\ ${ }^{c}$ European Commission c/o Max-Planck-Institut für Plasmaphysik, EURATOM Association, 85748 Garching, Germany
}

\begin{abstract}
The operation of W7-X stellarator for pulse length up to 30 minutes with $10 \mathrm{MW}$ input power requires a full set of actively water-cooled plasma facing components. From the lower thermally loaded area of the wall protection system designed for an averaged load of $100 \mathrm{~kW} / \mathrm{m}^{2}$ to the higher loaded area of the divertor up to $10 \mathrm{MW} / \mathrm{m}^{2}$, various design and technological solutions have been developed meeting the high load requirements and coping with the restricted available space and the particular 3D-shaped geometry of the plasma vessel. 80 ports are dedicated alone to the water-cooling of plasma facing components and a complex networking of kilometers of pipework will be installed in the plasma vessel to connect all components to the cooling system. An advanced technology was developed in collaboration with industry for the target elements of the high heat flux (HHF) divertor, the so-called "bi-layer" technology for the bonding of flat tiles made from CFC NB31 onto the CuCrZr cooling structure. The design, $R \& D$ and the adopted technological solutions of plasma facing components are presented. At present, except the HHF divertor, most of plasma facing components has been already manufactured.
\end{abstract}

Keywords: Stellarator, Plasma Facing Components, Divertor, First Wall

\section{Introduction}

WENDELSTEIN 7-X (W7-X) is an experimental machine being assembled in Greifswald [1], north-east Germany, intended to demonstrate the reactor potential of the helical advanced stellarator type for steady-state operation [2]. W7-X is equipped with a superconducting magnet system, a high power heating system and actively water-cooled plasma facing components (PFCs) including a divertor. The machine is designed for steadystate operation with $10 \mathrm{MW}$ input power over a pulse length of up to 30 minutes and peak power of up to 20 MW for 10 seconds.

The PFCs and the water-cooling system were originally designed to provide a reliable exhaust of the power and particle fluxes for high power steady-state operation [3]. In the meantime an intermediary stage was introduced [4]. The purpose of this initial phase is to prepare the final steady-state operation by studying different scenarios with plasma discharges of short pulse duration. For the PFCs, this new approach meant the development of an additional component, a temporary test divertor [5], designed to be adiabatically cooled, and has the same geometry as the one for steady-state operation. All other PFCs are designed for steady-state operation.

\section{Plasma Facing Components}

\subsection{Design}

The PFCs are the divertor components and the first wall protection system [6, 7]. The divertor consists of ten similar discrete units, two units per period, to keep the machine symmetry. The divertor geometry is an open configuration with horizontal and vertical parts that define the main pumping gap. The divertor components consist of the target areas where the energy is dissipated, the baffle area which helps to concentrate the neutral flux particles in the pumping gap, and the closures of the divertor chamber in the poloidal and the toroidal directions. Behind each of the ten target units are located a control coil and a cryo-vacuum pump system. The other PFCs include the heat shields and the panels covering the vessel, the piping system inside the plasma vessel that connects the PFCs to the water pipes, and the plug-ins in the ports for the water supply as well as the port protections. Special solutions have been developed at some locations to take into account the requirements of the heating and diagnostic systems. Of the 244 ports 80 ports are allocated to the water-cooling of plasma facing components.

\subsection{Technologies}

W7-X PFCs are designed to be covered with low-Z (carbon-based) plasma facing material. The technologies were selected according to the magnitude and spread of the heat loads (Fig. 1). The location of the various components is shown in Fig. 2 \& 4.

The same technology is used for the different PFCs. The fine graphite or CFC tiles are clamped onto a CuCrZr heat sink which is vacuum brazed to a stainless steel tube, a Sigraflex layer is used to improve thermal conductivity [8]. This technology is used for the baffles, the lower-loaded central part of the divertor, the heat shield wall protection on the inboard side closer to the plasma, the beam dump area for neutral beam injection (NBI) system, and the NBI \& Diagnostic-NBI ports. The 
geometrical ratio between tile and heat sink depends on the respective maximal heat loads.

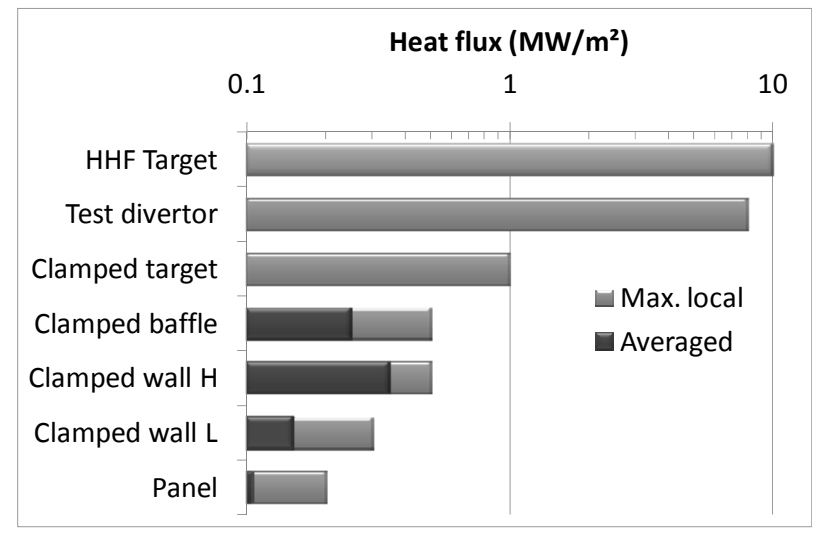

Fig.1 Range of heat fluxes specified per technology.

A module consists of a set of heat sinks brazed along a stainless steel cooling meander mounted onto a stainless steel support frame. The size of the module is restricted by the largest port size to allow exchange of components once the vessel is closed. The inboard side of the vessel with the highest curvature is located closer to the plasma. In this region, the averaged heat load (Fig. 1) is $350 \mathrm{~kW} / \mathrm{m}^{2}$ (clamped wall $\mathrm{H}$ ); otherwise, the value is $150 \mathrm{~kW} / \mathrm{m}^{2}$ (clamped wall $\mathrm{L}$ ). In this latter case, the maximal surface of the module is about $0.65 \mathrm{~m}^{2}$. The heat shields consist of 170 clamped modules; 70\% have been already manufactured.

Stainless steel panels protect the vacuum vessel in the main pumping gap, the poloidal divertor closure, and areas of lower radiated heat load. They are designed for an averaged heat load of $100 \mathrm{~kW} / \mathrm{m}^{2}$ and a maximal local one of $200 \mathrm{~kW} / \mathrm{m}^{2}$. About 320 panels are required and their delivery is nearly completed [9]. They will be installed without coating.

The temporary test divertor consists of fine graphite tiles attached with springs onto the support frame. The plasma facing contour is the same as for the steady state HHF divertor. It is planned to be used in the initial phase for high power short pulse operation. $8 \mathrm{MW} / \mathrm{m}^{2}$ were achieved for 6 sec. in HHF testing and confirmed the design.

The integration of the different PFCs in a divertor unit is illustrated in Fig. 2 for the initial phase. It includes: 3 vertical and 7 horizontal modules of the divertor, 2 clamped modules for the low loaded divertor targets, 9 vertical and 8 horizontal baffle modules, 9 panels for the poloidal closure, 2 clamped modules for the toroidal closure, 3 panels for the protection of the main pumping gap. There are ten such discrete units in W7-X. The installation allows for gaps between $3-5 \mathrm{~mm}$ between modules.

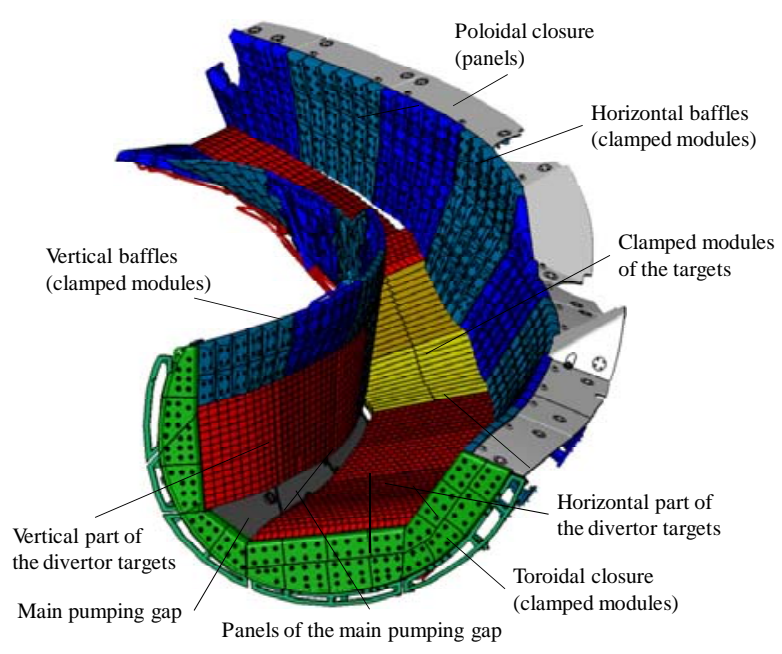

Fig.2 Different PFCs of the divertor unit.

The integrated areas of the various PFCs are given in Fig. 3. With the exception of special solutions for the NBI and Diagnostic-NBI systems [10], port protections will not be installed in the initial phase.

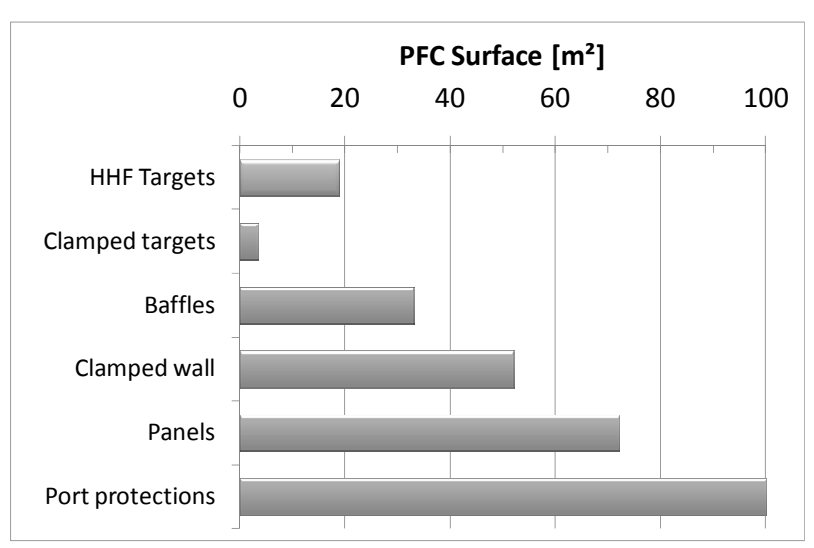

Fig.3 Surface of PFCs.

The uniqueness of $\mathrm{W} 7-\mathrm{X}$ is its $3 \mathrm{D}$ shape with a periodical change of the plasma cross section as one proceeds in the toroidal direction showing either a beanshaped or triangular-shaped contour within one period. $\mathrm{W} 7-\mathrm{X}$ has five periods. This periodic symmetry is, in addition, disrupted by the asymmetric positioning of heating and diagnostics systems as well as of the 244 machine ports. Fig. 4 shows the PFCs of the first wall protection from behind. This figure illustrates the complexity of the design and the lack of space in a 3D environment. It presents a view of the PFCs installed in one module of the plasma vessel; the machine consists of five modules. The plasma vessel is not shown and some PFCs have been removed to allow a better insight. Two divertor units, one located at the top and one at the bottom in a mirror symmetry are visible. The rear part of the divertor PFCs with the supporting frame and connection system to the consoles of the plasma vessel is shown. The outer vessel is protected with the first wall panels; the figure shows from the rear side the arrangement of the water cooling network located between the panels and the plasma vessel. The panels are fed in parallel from the dedicated ports. The higher loaded heat shields are located at the inboard side of the wall, closer to the plasma. A detailed description of the 
cooling system design inside the vessel can be found in [11]. The integration of the Rogowski coil and the glow discharge electrode in this machine module is also shown. The type of diagnostics is not the same between the different modules.

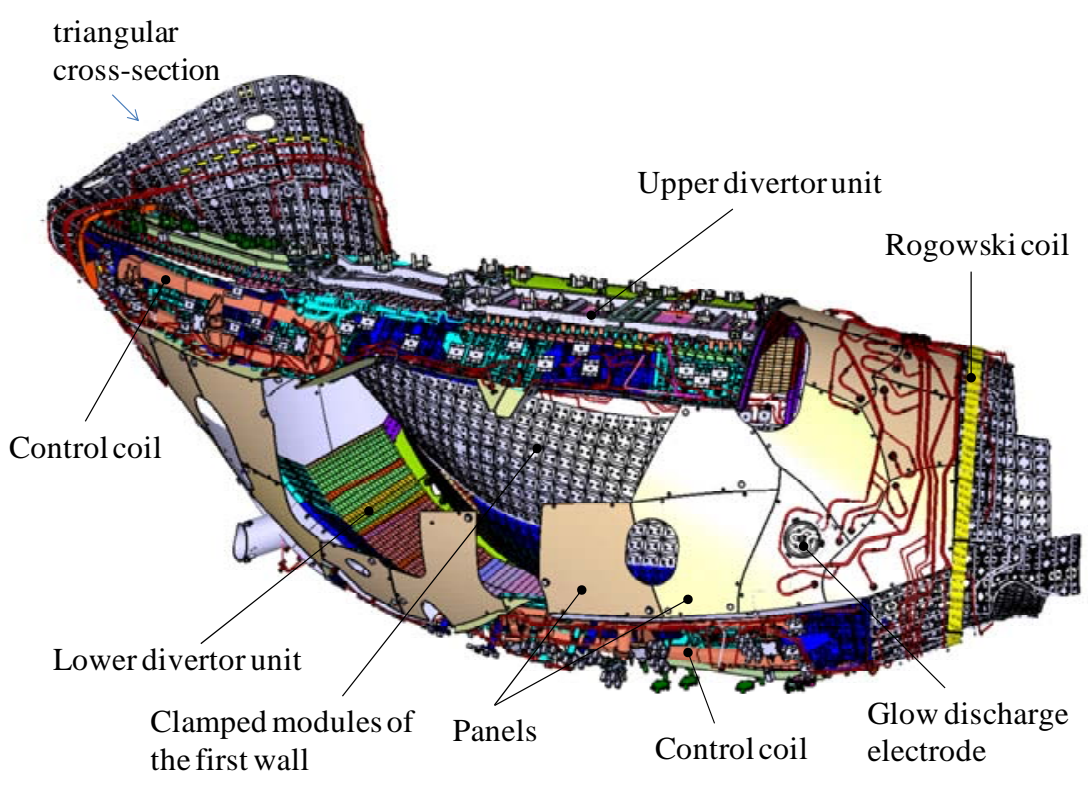

Fig.4. Arrangement of in vessel components for the plasma vessel module 1

\section{Target elements of the HHF divertor}

Certainly, the most demanding PFC is the high heat flux divertor. Its technical reliability is essential for the successful high power steady-state operation of the machine. The HHF divertor consists of 100 HHF target modules, ten per divertor unit. Each module is a set of 812 target elements mounted onto a support frame. The elements are fed in parallel from water manifolds. There are twelve different types of elements ranging from 250 to $600 \mathrm{~mm}$ length and 50 to $61.5 \mathrm{~mm}$ width. In total there are 890 elements.

The design of the target elements is based on the flat tile geometry. Flat tiles made from CFC NB31 [12] manufactured by Snecma Propulsion Solide (Bordeaux, France) are joined to a CuCrZr heat sink. The $19 \mathrm{~m}^{2}$ surface of the HHF divertor represents about 18,000 tiles. The initial approach was to use the experience gained during the production of the finger elements of the toroidal pump limiter of Tore Supra (Cadarache, France) $[13,14]$ and scale it to the W7-X divertor geometry to minimize R\&D activities. The manufacturer of the W7-X target elements is Plansee (Reutte, Austria). The strategy was to qualify the manufacturing of preseries elements and test them in the neutral beam test facility GLADIS [15] before launching the serial production. During the pre-series activities, 100\% of the elements were tested and must withstand 100 cycles @ $10 \mathrm{MW} / \mathrm{m}^{2}$ without any deterioration of their performances, such as the initiation of cracks at the interface between tiles and heat sink. After an intensive qualification phase with the manufacture of four pre- series amounting to about 60 full-scale elements and a strong collaboration with the manufacturer, the serial production was launched in 2009. The main achievement of these activities was the introduction and qualification of the bi-layer technology [16] instead of the AMC (Active Metal Casting) alone used for Tore Supra [17]. All elements of the last delivered pre-series met the specification after 100 cycles @ 10MW/m². Main results of additional testing beyond the specification on different elements can be summarized as follows: 10,000 cycles@10MW/m², 1000 cycles@16MW/m² without failure, testing up to $\sim 30 \mathrm{MW} / \mathrm{m}^{2}$ with strong carbon evaporation but no tile loss [18]. First elements of the series production will be delivered in 2011.

\section{Cooling loops for PFCs}

Three main cooling loops have been defined according to the function and the related loading of the different PFCs: one for the targets which requires the main coolant capacity, one for the baffle and one for the wall protection. Additional cooling loops are available for the control coils, the port protections, and for some diagnostics like the tomography cameras. The stainless steel plasma vessel is cooled by an independent system, but its heat removal capacity is limited. The thermal control of the plasma vessel is important. Thermal displacements of the PFCs with respect to the magnetic configuration have to be avoided and the thermal load to the cryostat has to be minimized.

In the initial phase 1 operation of W7-X with short high power plasma discharges, the cooling is only used for those areas of the wall where it is required: beam 
dumps for the NBI and the electron cyclotron resonance heating (ECRH) systems, housings of the glow discharge electrode, the diamagnetic loops, the multi-camera tomography system, NBI and Diagnostic-NBI ports, and the control coils. The temporary test divertor is installed and adiabatically cooled; the cryo-pumps and the port protections (except NBI \& Diagnostic-NBI) are not installed. All the pipe work amounting to about four kilometers of pipe work and the eighty plug-ins are installed but mostly not supplied. The external supply cooling system will not be installed. The difference between the phase 1 and the phase 2 operation in terms of water feeding is illustrated by Table 1 .

Table 1: Required maximal flow rate in $\mathrm{m}^{3} / \mathrm{h}$ per cooling loop for the two operation phases

\begin{tabular}{lcc}
\hline Cooling loop & Initial phase 1 & Operation phase 2 \\
\hline Target & - & $1380 / 1700$ \\
Baffle & 60 & 330 \\
Wall & 140 & 470 \\
\hline
\end{tabular}

The cooling loops have been designed for the second phase of operation but will be used at a reduced level during the initial phase of short pulse operation. Cooling for the target will not be installed because the targets are adiabatically cooled. The main cooling parameters for PFCs are listed in Table 2.

Table 2: PFC cooling parameters for plasma operation. Values in Italic are only valid for the phase 2 .

\begin{tabular}{lccc}
\hline PFC & $\begin{array}{c}\text { Velocity } \\
{[\mathrm{m} / \mathrm{s}]}\end{array}$ & $\begin{array}{c}\text { Tin } \\
{\left[{ }^{\circ} \mathrm{C}\right]}\end{array}$ & $\begin{array}{c}\text { Pin } \\
{[\mathrm{MPa}]}\end{array}$ \\
\hline Target & $8-10$ & 30 & 2.8 \\
Baffle & 6 & 35 & 2.0 \\
Clamped wall & 6 & $35-120$ & 2.0 \\
Panel & 2 & $35-120$ & 2.0 \\
\hline
\end{tabular}

For all PFCs, the maximal allowed temperature increase of the coolant is $50 \mathrm{~K}$. At the flange of each individual cooling circuit, the maximal pressure drop is 1.4 $\mathrm{MPa}$ for the target modules, and $1 \mathrm{MPa}$ for others, the static pressure is $1 \mathrm{MPa}$. The baking temperature is $150^{\circ} \mathrm{C}$. The loops have been designed to cope with the various modes of plasma operation of phase 2: normal, full-load and hot liner. They are designed to cover the extremes of the specified range of operation: from the low density operation with almost full power loading on the divertor targets to a more homogeneous distribution of the power load to the inner wall under conditions of high radiative losses (unloading of the divertor) corresponding to high density operation.

Normal operation represents about $70 \%$ of the experimental activities. The main heating system is ECRH; ICRH and NBI only work for ten seconds every three minutes. In this case, the water velocity in the target elements is $8 \mathrm{~m} / \mathrm{s}$ (corresponding to $1380 \mathrm{~m}^{3} / \mathrm{h}$ in Table 1). In full-load operation (about $10 \%$ of the discharges), the pulse length with full available power is 30 minutes. The water velocity in the target elements is increased to $10 \mathrm{~m} / \mathrm{s}$ (corresponding to $1700 \mathrm{~m}^{3} / \mathrm{h}$ in Table 1 ) because the local heat loads on the targets may reach $12 \mathrm{MW} / \mathrm{m}^{2}$.

The purpose of the hot liner operation with an increase of the inlet cooling temperature of the first wall to $120^{\circ} \mathrm{C}$ (see Table 2) is to reach a fast balance between adsorbed and desorbed particles at the wall. These conditions are not compatible with the operation of some in vessel diagnostics such as the diamagnetic loops and the multi-camera tomography system. Therefore, the baffle cooling loop also includes not only the baffles but also parts of the wall which are operated at a normal inlet temperature during hot liner operation.

\section{Conclusion}

The PFCs of W7-X, including an open divertor geometry, have been designed to allow high power steady-state operation for the study of a wide range of magnetic configuration and plasma parameters. Different technologies have been used to allow for a range of heat loads from $100 \mathrm{~kW} / \mathrm{m}^{2}$ to $10 \mathrm{MW} / \mathrm{m}^{2}$. The design has to cope with the restricted available space and the particular 3D shape of W7-X. Intensive $R \& D$ activities were carried out to develop the PFCs and in particular the HHF target elements. In the initial phase of short pulse duration, a temporary test divertor will be installed. Most of PFCs and their cooling system designed for the second phase will also be initially installed. This complex system will be operated at a reduced level during phase 1 . The installation of the actively-cooled HHF divertor in the second phase will allow the fulfillment of the mission of W7-X, the demonstration of the steady-state high power capability of the stellarator line.

\section{References}

[1] L. Wegener, Status of Wendelstein 7-X construction, Fusion Eng. Design 84, 106 (2009)

[2] G. Grieger et al., Physics of Fluids B4, 2081 (1992).

[3] H. Renner et al., Nuclear Fusion 40 (6), 1083 (2000).

[4] H. S. Bosch et al., Contrib. Plasma Phys. 50 (8), 687 (2010).

[5] A. Peacock et al. Fusion Eng. Design 84, 1475 (2009).

[6] B. Streibl et al., Fusion Eng. Design 75-79, 463 (2005).

[7] R. Stadler et al., Fusion Eng. Design 84, 305 (2009).

[8] H. Greuner et al., Fusion Eng. Design 66-68, 447 (2003).

[9] A. Peacock et al., this conference.

[10] N. Rust et al., this conference.

[11] B. Mendelevitch et al., this conference.

[12] G. Pintsuk et al., Fusion Eng. Design 84, 1525 (2009).

[13] J. J. Cordier et al., Fusion Eng. Design 66-68, 59 (2003).

[14] M. Lipa et al., Fusion Science Technol. 56, 1124 (2009).

[15] H. Greuner et al., J. Nucl. Materials 367-370, 1444 (2007).

[16] H. Greuner et al., this conference.

[17] J. Boscary et al., Fusion Eng. Design 84, 497 (2009).

[18] M. Missirlian et al., this conference. 